\title{
MENENTUKAN MATRIKS INVERS POSITIF DENGAN MENGGUNAKAN INVERS BANACHIEWICZ
}

\author{
RIDHA FADHILA SANI, YANITA, ADMI NAZRA \\ Program Studi S1 Matematika, \\ Fakultas Matematika dan Ilmu Pengetahuan Alam, Universitas Andalas, \\ Kampus UNAND Limau Manis Padang, Indonesia. \\ email : ridhafadhilasani95@gmail.com,yanita@sci.unand.ac.id,nazra@sci.unand.ac.id
}

\author{
Diterima 17 Februari 2020 Direvisi 7 Maret 2020 Dipublikasikan 29 April 2020
}

\begin{abstract}
Abstrak. Penelitian ini membahas tentang penentuan matriks invers positif menggunakan invers Banachiewicz. Matriks invers positif didefinisikan sebagai suatu matriks partisi $N$ yang merupakan matriks $Z$ (matriks yang elemen non-diagonalnya non-positif) yang memiliki invers dan invers dari matriks partisi $N$ tersebut memiliki entri-entri yang bernilai positif. Pada penelitian ini dikaji kondisi-kondisi yang mengakibatkan matriks partisi $N$ tersebut dapat dikatakan sebagai matriks invers positif yaitu dimana matriks partisi $N$ cukup memenuhi kondisi Georgescu-Roegen dimana seluruh leading minor utama adalah positif.

Kata Kunci: Matriks partisi, matriks invers positif, invers Banachiewicz, minor utama, leading minor utama, dan kondisi Georgescu-Roegen
\end{abstract}

\section{Pendahuluan}

Matriks adalah salah satu konsep dalam ilmu matematika. Pembahasan tentang matriks meliputi penentuan determinan, penentuan invers dan teori-teori yang terkait seperti menentukan nilai eigen dan vektor eigen. Selain itu matriks juga dapat digunakan untuk menyelesaikan sistem persamaan linier (SPL).

Penentuan invers matriks dilakukan dengan cara melakukan operasi baris elementer ataupun menggunakan metode matriks adjoin (adjoint) [1]. Metode lain yang sering digunakan untuk menentukan invers matriks adalah dengan menggunakan invers Banachiewicz [8].

Pada makalah ini akan dibahas kembali tentang penentuan invers-positif dari matriks $\mathrm{Z}$ yang berukuran $\mathbb{R}^{n \times n}$, yang entri-entri non-diagonalnya adalah nonpositif dengan menggunakan invers Banachiewicz [8]. Georgescu-Roegen berpendapat bahwa suatu matriks $\mathrm{Z}$ hanya cukup memiliki leading minor utama positif. Kemuadian suatu matriks $\mathrm{N}$ yang juga merupakan matriks $\mathrm{Z}$ dengan $n \geqslant 1$ akan memiliki invers positif jika dan hanya jika kondisi Georgescu-Roegen terpenuhi. Ini berarti seluruh leading minor utama adalah positif [9].

${ }^{*}$ penulis korespondensi 
170 Ridha Fadhila Sani dkk

\section{Landasan Teori}

\subsection{Matriks dan Operasi Matriks}

Matriks merupakan susunan dari suatu bilangan berbentuk persegi atau persegi panjang yang terdiri dari baris dan kolom. Matriks dengan a baris dan b kolom dituliskan sebagai berikut :

$$
M=\left[m_{i j}\right],
$$

dengan $1 \leqslant i \leqslant a$ dan $1 \leqslant j \leqslant b$. Bilangan-bilangan dalam susunan tersebut dinamakan entri matriks. Matriks biasanya dinotasikan menggunakan huruf kapital.[4].

\subsection{Operasi Baris Elementer}

Operasi baris elementer adalah operasi yang dilakukan pada baris suatu matriks. Ada tiga jenis operasi baris elementer, yaitu:

(1) Pertukaran baris.

(2) Perkalian suatu baris dengan konstanta tak nol.

(3) Penjumlahan hasil perkalian suatu baris deengan konstanta tak nol dengan baris yang lain.

\subsection{Invers Matriks}

Jika $M$ adalah matriks bujursangkar, dan jika terdapat matriks $B$ yang ukurannya sama sedemikian sehingga $M B=B M=I$, maka matriks $M$ dapat dibalik dan matriks $B$ disebut sebagai invers dari matriks $M$, dan matriks $B$ dapat ditulis sebagai $M^{-1}$. Jika matriks $B$ bukan invers dari matriks $M$, maka matriks $M$ dinyatakan sebagai matriks singular (matriks yang determinannya sama dengan nol). [1]

\subsection{Matriks Blok}

Matriks blok atau matriks partisi adalah matriks yang dipecah (diblok) disebut sebagai sub-matriks. [7]

\subsection{Determinan Matriks dan Determinan Matriks Blok}

Definisi 2.1. [1] Misalkan $M$ adalah matriks berukuran $n \times n$. Hasil kali elementer bertanda dari matriks $M$ berukuran $n \times n$ adalah hasil kali $n$ buah unsur dari matriks $M$ tanpa ada pengambilan unsur dari baris dan kolom yang sama yang diberi tanda (+1) jika permutasinya genap dan (-1) jika permutasinya ganjil.

Definisi 2.2. [1] Misalkan $M$ adalah matriks berukuran $n \times n$. Fungsi determinan dari matriks $M$, dinotasikan dengan $\operatorname{det}(M) \cdot \operatorname{det}(M)$ adalah jumlah dari semua hasilkali elementer bertanda dari matriks $M$. Angka $\operatorname{det}(M)$ disebut sebagai determinan dari $M$.

Teorema 2.3. [5] Jika $M$ merupakan matriks $n \times n$ dan $M=\left[\begin{array}{ll}A & B \\ C & D\end{array}\right]$, dengan $A \in \mathbb{R}^{n \times n}, B \in \mathbb{R}^{n \times t}, C \in \mathbb{R}^{s \times n}$, dan $D \in \mathbb{R}^{s \times t}$, maka $\operatorname{det}(M)$ adalah: 
(a) $\operatorname{det}(M)=\operatorname{det}\left[\begin{array}{ll}A & B \\ C & D\end{array}\right]=\operatorname{det}(A) \cdot \operatorname{det}\left(D-C A^{-1} B\right)$, jika A memiliki invers, atau

(b) $\operatorname{det}(M)=\operatorname{det}\left[\begin{array}{ll}A & B \\ C & D\end{array}\right]=\operatorname{det}(D) \cdot \operatorname{det}\left(A-B D^{-1} C\right)$, jika $D$ memiliki invers.

\subsection{Leading Minor Utama}

Misalkan $M$ adalah matriks berukuran $n \times n$. $P_{k}$ adalah sebuah minor utama ke-k dari matriks $M$, dimana $P_{k}$ diperoleh dari penghapusan $(n-k)$ baris dan $(n-$ $k$ ) kolom dengan baris dan kolom yang sama, lalu dideterminankan matriks yang tersisa. Selanjutnya, $Q_{k}$ adalah sebuah leading minor utama ke-k dari matriks $M$, dimana $Q_{k}$ diperoleh dari penghapusan $(n-k)$ baris dan $(n-k)$ kolom yang terakhir, lalu dideterminankan matriks yang tersisa. [6]

\section{Pembahasan}

\subsection{Komplemen Schur dan Identitas Banachiewicz}

Definisi 3.1. [6] Misalkan matriks $M \in \mathbb{R}^{n \times n}$ adalah matriks partisi dan matriks $M$ dipartisi menjadi empat partisi. Matriks $M$ dapat ditulis sebagai berikut :

$$
M=\left[\begin{array}{ll}
A & B \\
C & D
\end{array}\right],
$$

dengan $A \in \mathbb{R}^{n \times n}, B \in \mathbb{R}^{n \times t}, C \in \mathbb{R}^{s \times n}$, dan $D \in \mathbb{R}^{s \times t}$, maka komplemen Schur dari $A$ pada $M$ didefinisikan sebagai berikut:

$$
S=(M / A)=D-C A^{-1} B,
$$

dengan asumsi bahwa matriks $A$ dapat dibalik.

Selanjutnya, untuk kasus khusus, matriks $N \in \mathbb{R}^{n \times n}$ adalah matriks partisi. Matriks $N$ dapat ditulis sebagai berikut:

$$
N=\left[\begin{array}{cc}
E & F \\
G & a_{n n}
\end{array}\right],
$$

dengan $E \in \mathbb{R}^{(n-1) \times(n-1)}, F \in \mathbb{R}^{(n-1) \times 1}, G \in \mathbb{R}^{1 \times(n-1)}$, dan $a_{n n} \in \mathbb{R}^{1 \times 1}$, maka komplemen Schur dari E pada $N$ didefinisikan sebagai berikut:

$$
S=(N / E)=a_{n n}-G E^{-1} F,
$$

dengan asumsi bahwa matriks E dapat dibalik.

Teorema 3.2. [6](Invers Banachiewicz).

Misalkan matriks $N$ adalah matriks persegi yang didefinisikan seperti pada persamaan (3.1) sebagai berikut :

$$
N=\left[\begin{array}{cc}
E & F \\
G & a_{n n}
\end{array}\right],
$$


dengan $E \in \mathbb{R}^{(n-1) \times(n-1)}, F \in \mathbb{R}^{(n-1) \times 1}, G \in \mathbb{R}^{1 \times(n-1)}$, dan $a_{n n} \in \mathbb{R}^{1 \times 1}$. Jika $E^{-1}$ dan $(N / E)^{-1}$ ada, serta matriks $N$ invertibel, maka $N^{-1}$ diberikan sebagai berikut :

$$
N^{-1}=\left[\begin{array}{cc}
E^{-1}+E^{-1} F S^{-1} G E^{-1}-E^{-1} F S^{-1} \\
-S^{-1} G E^{-1} & S^{-1}
\end{array}\right],
$$

dengan

$$
S=(N / E)=a_{n n}-G E^{-1} F .
$$

Bukti. Akan dibuktikan $N N^{-1}=N^{-1} N=I$.

Akan ditunjukkan $N N^{-1}=I$, yaitu:

$$
\begin{aligned}
N N^{-1} & =\left[\begin{array}{cc}
E & F \\
G & a_{n n}
\end{array}\right]\left[\begin{array}{cc}
E^{-1}+E^{-1} F S^{-1} G E^{-1}-E^{-1} F S^{-1} \\
-S^{-1} G E^{-1} & S^{-1}
\end{array}\right] \\
& =\left[\begin{array}{cc}
E\left(E^{-1}+E^{-1} F S^{-1} G E^{-1}\right)+F\left(-S^{-1} G E^{-1}\right) & E\left(-E^{-1} F S^{-1}\right)+F\left(S^{-1}\right) \\
G\left(E^{-1}+E^{-1} F S^{-1} G E^{-1}\right)+a_{n n}\left(-S^{-1} G E^{-1}\right) & G\left(-E^{-1} F S^{-1}\right)+a_{n n}\left(S^{-1}\right)
\end{array}\right] \\
& =\left[\begin{array}{cc}
E E^{-1}+E E^{-1} F S^{-1} G E^{-1}-F S^{-1} G E^{-1} & -E E^{-1} F S^{-1}+F S^{-1} \\
G E^{-1}+G E^{-1} F S^{-1} G E^{-1}-a_{n n} S^{-1} G E^{-1} & -G E^{-1} F S^{-1}+a_{n n} S^{-1}
\end{array}\right] \\
& =\left[\begin{array}{cc}
I+I F S^{-1} G E^{-1}-F S^{-1} G E^{-1} & -I F S^{-1}+F S^{-1} \\
G E^{-1}+G E^{-1} F S^{-1} G E^{-1}-a_{n n} S^{-1} G E^{-1} & -G E^{-1} F S^{-1}+a_{n n} S^{-1}
\end{array}\right]
\end{aligned}
$$

Perhatikan bahwa :

$$
\begin{aligned}
I+I F S^{-1} G E^{-1}-F S^{-1} G E^{-1} & =I+\left(F S^{-1} G E^{-1}\right)(I-I) \\
& =I_{(n-1) \times(n-1)} \\
-I F S^{-1}+F S^{-1} & =F S^{-1}(-I+I) \\
& =\mathbf{0}_{(n-1) \times 1} \\
G E^{-1}+G E^{-1} F S^{-1} G E^{-1}-a_{n n} S^{-1} G E^{-1} & =G E^{-1}\left(I+G E^{-1} F S^{-1}-a_{n n} S^{-1}\right) \\
& =G E^{-1}\left(I-S^{-1}\left(a_{n n}-G E^{-1} F\right)\right) \\
& =G E^{-1}\left(I-S^{-1} S\right) \\
& =G E^{-1}(I-I) \\
& =\mathbf{0}_{1 \times(n-1)} \\
-G E^{-1} F S^{-1}+a_{n n} S^{-1} & =S^{-1}\left(a_{n n}-G E^{-1} F\right) \\
& =S^{-1} S \\
& =I_{1 \times 1} .
\end{aligned}
$$

Dari persamaan (3.2), (3.3), (3.4), dan (3.5), diperoleh :

$$
N N^{-1}=\left[\begin{array}{cc}
I_{(n-1) \times(n-1)} & \mathbf{0}_{(n-1) \times 1} \\
\mathbf{0}_{1 \times(n-1)} & I_{1 \times 1}
\end{array}\right]=I_{n \times n},
$$

sehingga terbukti bahwa $N N^{-1}=I$.

Selanjutnya, akan ditunjukkan $N^{-1} N=I$, yaitu: 


$$
\begin{aligned}
& N^{-1} N=\left[\begin{array}{cc}
E^{-1}+E^{-1} F S^{-1} G E^{-1}-E^{-1} F S^{-1} \\
-S^{-1} G E^{-1} & S^{-1}
\end{array}\right]\left[\begin{array}{cc}
E & F \\
G & a_{n n}
\end{array}\right], \\
& =\left[\begin{array}{cc}
\left(E^{-1}+E^{-1} F S^{-1} G E^{-1}\right) E+\left(-E^{-1} F S^{-1}\right) G\left(E^{-1}+E^{-1} F S^{-1} G E^{-1}\right) F+\left(-E^{-1} F S^{-1}\right) a_{n n} \\
\left(-S^{-1} G E^{-1}\right) E+\left(S^{-1}\right) G & \left(-S^{-1} G E^{-1}\right) F+\left(S^{-1}\right) a_{n n}
\end{array}\right] \\
& =\left[\begin{array}{cc}
E^{-1} E+E^{-1} F S^{-1} G E^{-1} E-E^{-1} F S^{-1} G E^{-1} F+E^{-1} F S^{-1} G E^{-1} F-E^{-1} F S^{-1} a_{n n} \\
-S^{-1} G E^{-1} E+S^{-1} G & -S^{-1} G E^{-1} F+S^{-1} a_{n n}
\end{array}\right] \\
& =\left[\begin{array}{cc}
I+E^{-1} F S^{-1} G I-E^{-1} F S^{-1} G E^{-1} F+E^{-1} F S^{-1} G E^{-1} F-E^{-1} F S^{-1} a_{n n} \\
-S^{-1} G I+S^{-1} G & -S^{-1} G E^{-1} F+S^{-1} a_{n n}
\end{array}\right]
\end{aligned}
$$

Perhatikan bahwa :

$$
\begin{aligned}
I+E^{-1} F S^{-1} G I-E^{-1} F S^{-1} G & =I+\left(E^{-1} F S^{-1} G\right)(I-I) \\
& =I_{(n-1) \times(n-1)} \\
E^{-1} F+E^{-1} F S^{-1} G E^{-1} F-E^{-1} F S^{-1} a_{n n} & =E^{-1} F\left(I+S^{-1} G E^{-1} F-S^{-1} a_{n n}\right) \\
& =E^{-1} F\left(I+S^{-1}\left(G E^{-1} F-a_{n n}\right)\right) \\
& =E^{-1} F\left(I+S^{-1}(-S)\right) \\
& =E^{-1} F(I-I) \\
& =\mathbf{0}_{(n-1) \times 1} \\
-S^{-1} G I+S^{-1} G & =S^{-1} G(-I+I) \\
& =\mathbf{0}_{1 \times(n-1)} \\
\left(-S^{-1} G E^{-1}\right) F+\left(S^{-1}\right) a_{n n} & =S^{-1}\left(-G E^{-1} F+a_{n n}\right) \\
& =S^{-1} S \\
& =I_{1 \times 1} .
\end{aligned}
$$

Dari persamaan (3.6), (3.7), (3.8), dan (3.9), diperoleh :

$$
N^{-1} N=\left[\begin{array}{cc}
I_{(n-1) \times(n-1)} & \mathbf{0}_{(n-1) \times 1} \\
\mathbf{0}_{1 \times(n-1)} & I_{1 \times 1}
\end{array}\right]=I_{n \times n},
$$

sehingga, terbukti bahwa $N^{-1} N=I$.

\subsection{Matriks Invers-Positif}

Definisi 3.3. [2] Sebuah matriks persegi $N$ dikatakan sebagai matriks invers-positif jika $N$ memiliki invers dan $N^{-1}>\boldsymbol{O}$.

Proposisi 3.4. [8] Misalkan $N$ adalah matriks seperti pada persamaan (3.1). Misalkan bahwa $E^{-1}>\boldsymbol{O}$ dan $|E|>0$, maka $N$ adalah invers-positif jika dan hanya jika $|N|>0, E^{-1}+E^{-1} F S^{-1} G E^{-1} \geqslant \boldsymbol{0},-E^{-1} F S^{-1} \geqslant \boldsymbol{0}$, dan $-S^{-1} G E^{-1} \geqslant \boldsymbol{0}$.

Bukti. ( $\Longrightarrow$ ) Misalkan bahwa $E^{-1}>\mathbf{0},|E|>0$ dan $N^{-1}>\mathbf{0}$. Akan dibuktikan bahwa $|N|>0, E^{-1}+E^{-1} F S^{-1} G E^{-1} \geqslant \mathbf{0},-E^{-1} F S^{-1} \geqslant \mathbf{0}, \operatorname{dan}-S^{-1} G E^{-1} \geqslant \mathbf{0}$. Oleh karena $N^{-1}>\mathbf{0}$ maka $N^{-1}=\left[\begin{array}{c}E^{-1}+E^{-1} F S^{-1} G E^{-1}-E^{-1} F S^{-1} \\ -S^{-1} G E^{-1}\end{array}\right]>\mathbf{0}$, dengan $E^{-1}+E^{-1} F S^{-1} G E^{-1}>\mathbf{0},-E^{-1} F S^{-1}>\mathbf{0},-S^{-1} G E^{-1}>\mathbf{0}$, dan $S^{-1}>0$. Oleh karena $S^{-1}>0$ maka $S>0$, dengan $S^{-1}$ dan $S$ adalah skalar. Selanjutnya, karena 
$S>0$ maka $|S|>0$. Berdasarkan Teorema 2.3(a.), karena $|S|>0$ dan $|E|>0$ maka terbukti bahwa $|N|>0$.

$(\Longleftarrow)$ Misalkan bahwa $E^{-1}>\mathbf{0},|E|>0$. Misalkan $|N|>0, E^{-1}+E^{-1} F S^{-1}$ $G E^{-1} \geqslant \mathbf{0},-E^{-1} F S^{-1} \geqslant \mathbf{0}$, dan $-S^{-1} G E^{-1} \geqslant \mathbf{0}$. Akan dibuktikan bahwa $N^{-1}$ $>\mathbf{0}$. Selanjutnya, karena akan dibuktikan $N^{-1}>\mathbf{0}$ maka akan dibuktikan bahwa $E^{-1}+E^{-1} F S^{-1} G E^{-1}>\mathbf{0},-E^{-1} F S^{-1}>\mathbf{0},-S^{-1} G E^{-1}>\mathbf{0}$, dan $S^{-1}>0$, jelas dari asumsi. Untuk membuktikan $N^{-1}>\mathbf{0}$, maka kita tinggal membuktikan $S^{-1}>0$. Berdasarkan Teorema 2.3(a.), karena $|E|>0$ dan $|N|>0$ maka $|S|>0$, dengan $S$ adalah skalar.

Oleh karena $S$ adalah skalar dan $|S|>0$ maka $S>0$. Oleh karena $S>0$ maka $S^{-1}$ $>0$. Selanjutnya, karena $S^{-1}>0$ maka terbukti bahwa $N^{-1}>\mathbf{0}$.

Teorema 3.5. [8] Misalkan $N$ adalah matriks seperti pada persamaan (3.1). Misalkan bahwa $E^{-1}>\boldsymbol{O},|E|>0, F \leqslant \boldsymbol{O}$, dan $G \leqslant \boldsymbol{O}$, maka $|N|>0$ jika dan hanya jika $N^{-1}>\boldsymbol{O}$.

Bukti. Misalkan bahwa $E^{-1}>\mathbf{0},|E|>0, F \leqslant \mathbf{0}$, dan $G \leqslant \mathbf{0}$.

$(\Longrightarrow)$ Misalkan $|N|>0$ maka akan dibuktikan $N^{-1}>\mathbf{0}$.

Misalkan $|N|>0$. Berdasarkan Teorema 2.3(a.), karena $|E|>0$ dan $|N|>0$ maka $|S|>0$. Oleh karena $|S|>0$ maka $S^{-1}>0$, dengan $S$ dan $S^{-1}$ adalah skalar. Oleh karena $S^{-1}>0, E^{-1}>\mathbf{0}, F \leqslant \mathbf{0}$, dan $G \leqslant \mathbf{0}$ maka $E^{-1}+E^{-1} F$ $S^{-1} G E^{-1}>\mathbf{0},-E^{-1} F S^{-1} \geqslant \mathbf{0},-S^{-1} G E^{-1} \geqslant \mathbf{0}$, dan $S^{-1}>0$. Oleh karena $E^{-1}+E^{-1} F S^{-1} G E^{-1}>\mathbf{0},-E^{-1} F S^{-1} \geqslant \mathbf{0},-S^{-1} G E^{-1} \geqslant \mathbf{0}$, dan $S^{-1}>0$ maka terbukti bahwa $N^{-1}>\mathbf{0}$.

$(\Longleftarrow)$ Misalkan $N^{-1}>\mathbf{0}$ maka akan dibuktikan $|N|>0$. Berdasarkan Teorema 3.2, misalkan $N^{-1}>\mathbf{0}$ maka $E^{-1}+E^{-1} F S^{-1} G E^{-1}>\mathbf{0},-E^{-1} F S^{-1}>\mathbf{0},-S^{-1} G$ $E^{-1}>\mathbf{0}$, dan $S^{-1}>0$. Oleh karena $S^{-1}>0$ maka $S>0$, dengan $S$ dan $S^{-1}$ adalah skalar. Oleh karena $S>0$ maka $|S|>0$. Berdasarkan Teorema 2.3(a.), karena $|S|>0$ dan $|E|>0$ maka terbukti bahwa $|N|>0$.

Akibat 3.6. [8] Diberikan matriks $N$ berukuran $n \times n$ adalah matriks- $Z$ (matriks dengan elemen non-diagonalnya non-positif) dengan $n \geqslant 1$, maka $N$ invers-positif jika dan hanya jika kondisi Georgescu-Roegen terpenuhi, dengan kata lain seluruh leading minor utama dari matriks $N$ adalah positif.

Bukti. Misalkan matriks $\mathrm{N}$ berukuran $n \times n$ adalah matriks- $\mathrm{Z}$ (matriks dengan elemen non-diagonalnya non-positif) dengan $n \geqslant 1$. Selanjutnya matriks $N$ dipartisi menjadi:

$$
N=\left[\begin{array}{cc}
E & F \\
G & a_{n n}
\end{array}\right]
$$

dengan $E \in \mathbb{R}^{(n-1) \times(n-1)}, F \in \mathbb{R}^{(n-1) \times 1}, G \in \mathbb{R}^{1 \times(n-1)}$, dan $a_{n n} \in \mathbb{R}^{1 \times 1}$.

$(\Longrightarrow)$ Misalkan matriks $N^{-1}>\mathbf{0}$ atau matriks $N^{-1}$ dapat ditulis sebagai berikut:

$$
N^{-1}=\left[\begin{array}{cc}
E^{-1}+E^{-1} F S^{-1} G E^{-1}-E^{-1} F S^{-1} \\
-S^{-1} G E^{-1} & S^{-1}
\end{array}\right]>\mathbf{0},
$$


dengan

$$
S=(N / E)=a_{n n}-G E^{-1} F
$$

Akan dibuktikan kondisi Georgescu-Roegen terpenuhi, dengan kata lain seluruh leading minor utama adalah positif.

Pembuktian menggunakan Induksi Matematika sebagai berikut. Akan dibuktikan bahwa $\mathrm{P}(\mathrm{n})$ berikut untuk $n \geqslant 1$.

$P(n)$ : leading minor utama ke-n dari matriks $N$ bernilai positif.

(1) Langkah Basis

Untuk $\mathrm{P}(1)$, leading minor utama ke-1 adalah $\left|a_{11}\right|$. Oleh karena matriks $N$ adalah matriks $Z$ maka $a_{11}>0$. Oleh karena $a_{11}>0$ maka $\left|a_{11}\right|>0$.

(2) Langkah Induksi

Misalkan P(n-1) benar, yaitu $\left|\begin{array}{ccc}a_{11} & \cdots & a_{1(n-1)} \\ \vdots & \cdots & \vdots \\ a_{(n-1) 1} & \cdots & a_{(n-1)(n-1)}\end{array}\right|>0$ atau $|E|>0$.

Akan dibuktikan $\mathrm{P}(\mathrm{n})$ juga benar, yaitu $\left|\begin{array}{ccc}a_{11} & \cdots & a_{1 n} \\ \vdots & \cdots & \vdots \\ a_{n 1} & \cdots & a_{n n}\end{array}\right|>0$ atau $|N|>$

0. Berdasarkan Teorema 3.2, asumsikan $E^{-1}$ ada dan $S^{-1}$ ada. Oleh karena $N^{-1}>\mathbf{0}$ maka $E^{-1}+E^{-1} F S^{-1} G E^{-1}>\mathbf{0},-E^{-1} F S^{-1}>\mathbf{0},-S^{-1} G E^{-1}>\mathbf{0}$ dan $S^{-1}>0$. Oleh karena $S^{-1}>0$ maka $S>0$, dengan $S^{-1}$ dan $S$ adalah skalar. Oleh karena $S>0$ maka $|S|>0$. Berdasarkan Teorema 2.3(a.), karena $|S|>0$ dan $|E|>0$ maka $|N|>0$. Oleh karena $\left|a_{11}\right|>0,|E|>0$ dan $|N|>0$ maka seluruh leading minor utama adalah positif, dengan kata lain bahwa kondisi Georgescu-Roegen terpenuhi.

$(\Longleftarrow)$ Misalkan kondisi Georgescu-Roegen terpenuhi, dengan kata lain seluruh leading minor utama bernilai positif, maka $\left|a_{11}\right|>0,|E|>0$ dan $|N|>0$. Berdasarkan Teorema 3.2, asumsikan $E^{-1}$ ada, $E^{-1}>\mathbf{0}$ dan $S^{-1}$ ada. Berdasarkan Teorema 2.3(a.), karena $|E|>0$ dan $|N|>0$ maka $|S|>0$. Oleh karena $|S|>0$ maka $S>0$. Oleh karena $S>0$ maka $S^{-1}>0$, dengan $S$ dan $S^{-1}$ adalah skalar. Oleh karena matriks $N$ berukuran $n \times n$ adalah matriks $Z$ dengan entri-entri selain $a_{11}, a_{22}, \cdots, a_{n n}$ adalah bernilai non-positif. Jadi, diperoleh $F \leqslant \mathbf{0}$ dan $G \leqslant \mathbf{0}$. Oleh karena $E^{-1}>\mathbf{0}, F \leqslant \mathbf{0}$ dan $G \leqslant \mathbf{0}$ maka $E^{-1}+E^{-1} F S^{-1} G E^{-1}>\mathbf{0}$, $-E^{-1} F S^{-1}>\mathbf{0}$ dan $-S^{-1} G E^{-1}>\mathbf{0}$. Oleh karena $E^{-1}+E^{-1} F S^{-1} G E^{-1}>\mathbf{0}$, $-E^{-1} F S^{-1}>\mathbf{0},-S^{-1} G E^{-1}>\mathbf{0}$ dan $S^{-1}>0$ maka $N^{-1}>\mathbf{0}$.

\section{Kesimpulan}

Misalkan terdapat matriks partisi $N$ dengan partisi sebagai berikut:

$$
N=\left[\begin{array}{cc}
E & F \\
G & a_{n n}
\end{array}\right]
$$


dimana $E \in \mathbb{R}^{(n-1) \times(n-1)}, F \in \mathbb{R}^{(n-1) \times 1}, G \in \mathbb{R}^{1 \times(n-1)}$, dan $a_{n n} \in \mathbb{R}^{1 \times 1}$. Maka $N^{-1}$ adalah:

$$
N^{-1}=\left[\begin{array}{cc}
E^{-1}+E^{-1} F S^{-1} G E^{-1} & -E^{-1} F S^{-1} \\
-S^{-1} G E^{-1} & S^{-1}
\end{array}\right],
$$

dimana komplemen Schur dari sub-matriks $E$ untuk matriks $N$ adalah

$$
S=(N / E)=a_{n n}-G E^{-1} F .
$$

Suatu matriks $N$ dapat dinayatakan sebagai matriks invers-positif bila terpenuhi yang pertama Proposisi 3.4 menyatakan bahwa seluruh sub-matriks dari $N^{-1}$ harus bernilai positif, yang kedua Teorema 3.5 menyatakan bahwa $|N|>0$ dan haruslah sub-matriks $N$ yaitu $F \leqslant \mathbf{0}$ dan $G \leqslant \mathbf{0}$, dan yang ketiga Akibat 3.6 menyatakan bahwa kondisi Georgescu-Roegen harus terpenuhi, yaitu setiap leading minor utama adalah positif.

\section{Daftar Pustaka}

[1] Anton, H and C. Rorres. 2005. Elementary Linier Algebra. Ninth Edition. John Wiley: New York.

[2] Berman, A and R.J. Plemmons. 1979. Nonnegative Matrices in the Mathematical Sciences. Academic Press: New York.

[3] Bill, J. 1990. Linear Algebra. W.H Freeman and Company: New York.

[4] Charles, C.G. 1992. Aljabar Linier dan Penerapannya. Gramedia Pustaka Utama: Jakarta.

[5] Meyer, C.D. 2000. Matrix Analysis and Applied Linear Algebra. SIAM: Philadelphia.

[6] Piziak, R and P.L Odell. 2007. Matriks Theory. From Generalized Inverses to Jordan Form. Chapman and Hall/CRC: Canada.

[7] Searle, S.R. 1928. Matrix Algebra Useful for Statistics. John Wiley and Sons: New York.

[8] Fujimoto, T. 2007. The Banachiewicz Identity and Inverse Positive Matrices. Fukuoka University Review of Economics. 51: 309 - 315.

[9] Georgescu, N and Roegen. 1951. Some Properties of A Generalized Leontief Model in Tjalling Koopmans(ed.). Activity Analysis of Allocation and Production. $165-173$. 